\title{
The Problem with Truthmaker-Gap Epistemicism
}

MARK JAGO

Forthcoming in Thought. Draft of March 2013.

Abstract: Epistemicism about vagueness is the view that vagueness, or indeterminacy, is an epistemic matter. Truthmaker-gap epistemicism is the view that indeterminate truths are indeterminate because their truth is not grounded by any worldly fact. Both epistemicism in general and truthmaker-gap epistemicism originated in Roy Sorensen's work on vagueness. My aim in this paper is to give a characterisation of truthmaker-gap epistemicism and argue that the view is incompatible with higher-order vagueness: vagueness in whether some case of the form 'it is determinate that $A$ ' or 'it is indeterminate whether $A$ ' is true. Since it is highly likely that there is higher-order vagueness (and indeed, Sorensen is adamant that there is higher-order vagueness), truthmaker-gap epistemicism is in an uncomfortable position.

Keywords: Vagueness, epistemicism, higher-order vagueness, truthmaking, grounding, Sorensen

\section{Introduction}

Epistemicism about vagueness is the view that a proposition's vagueness is an epistemic matter. Epistemicism holds that propositions about vague cases - or, as I'll say, indeterminate propositions - are always either true or false, but we cannot know which (Sorensen 200I, I3). Epistemicism, in its modern form, originated with Roy Sorensen (1988; I994; 200I) and Timothy Williamson (I994). One distinctive feature of epistemicism is its strict adherence to classical logic, and in particular, to a bivalent semantics with Boolean negation: every proposition is either true or false, but not both. As a consequence, each day there's a moment around noon - a noonish moment - and a moment just a nanosecond later which isn't noonish. ${ }^{\mathrm{I}}$ The argument is familiar: if there were no such moments then (assuming classical reasoning) it must be the case that if $n$ nanoseconds after noon is noonish, then so is $n+1$ nanoseconds after noon. Applying this principle enough times, we get the absurd conclusion that $6 \mathrm{pm}$ is noonish.

The classical features of epistemicism are at once its strength and its weakness. They are a strength because every non-classical approach to vagueness faces serious logical problems. ${ }^{2}$ They are a weakness because many find it inconceivable that there could be a sharp boundary between the noonish and the non-noonish moments. How could a mere nanosecond take us from a noonish to a non-noonish moment? As Sorensen says,

I. These cut-off points may change from context to context (Sorensen 200I, 2).

2. By way of example, some non-classical approaches treat classical tautologies as being less than fully true; some treat 'something is $F$ ' as true even when no particular thing is an $F$. 
many people believe the same truth-value must be assigned to sentence pairs of the form ' $n$ nanoseconds after noon is noonish' and ' $n+1$ nanoseconds after noon is noonish'. They dismiss that there could be a value for $n$ at which the first is true and the second is false: 'What could make the first true and the second false?' (Sorensen 200I, I76)

Sorensen (200I) then offers an interesting response to this worry for epistemicists. He agrees with the objector that nothing could possibly make ' $n$ nanoseconds after noon is noonish' true and ' $n+1$ nanoseconds after noon is noonish' false. Nevertheless, he holds that, for some value of $n$, the former is true and the latter is false. For this value, ' $n$ nanoseconds after noon is noonish' is true but is not made true: it is an ungrounded truth. These cases constitute the indeterminate truths, on Sorensen's truthmaker-gap view. The view supports Sorensen's brand of epistemicism, on which indeterminate truths absolutely unknowable (200I, I 2, I3, 39). If a truth has no grounding, then (at least in non-a priori cases) there is no way of coming to know that it is true. A belief in its truth would be similarly ungrounded - a lucky guess - and such true beliefs do not suffice for knowledge (Sorensen 200I, I7 I, I75). Indeterminate truths are absolutely unknowable because they are ungrounded truths. ${ }^{3}$

My aims in this paper are to provide a characterisation of truthmaker-gap epistemicism, including some of its formal details (which Sorensen does not do), and argue that the view is incompatible with higher-order vagueness: vagueness in whether some case of the form 'it is determinate that $A$ ' or 'it is indeterminate whether $A^{\prime}$ ' is true. This conclusion is serious for an epistemicist who wants to adopt the truthmaker-gap account, for it is very plausible that there are instances of higher-order vagueness. As Williamson says,

We have as much reason to acknowledge higher-order vagueness as we have to acknowledge first-order vagueness; the difficulty of applying the higher-order classifications to a sorites series is of just the same kind as the difficulty of applying the first-order classification, which was what led us to recognize the problem of vagueness in the first place. (Williamson I999, I27)

Moreover, epistemicism (in general) is perhaps the best-placed theory of vagueness to deal with higher-order vagueness. Theories which do not accept first-order sharp cutoffs nevertheless seem to be lumbered with higher-order sharp cutoffs (between degrees of truth, for example). This is often taken to be a strong argument in favour of epistemicism, but it is unavailable to the truthmaker-gap epistemicist if she also rejects higher-order vagueness. Quite aside from this point, adopting truthmaker-gap epistemicism whilst denying higher-order vagueness will leave one with an unprincipled, ad hoc metaphysics $\left(\mathbb{S}_{5}\right)$. I take it to be a serious flaw of truthmaker-gap epistemicism that it cannot accommodate higher-order

3. This account is not epistemicist in the sense of a theory on which vagueness consists in unknowability (Greenough 2008, 229). Rather, on the truthmaker-gap account, vagueness consists in ungrounded truth. The unknowability of such truths is a consequence of their lack of grounding and hence a consequence, rather than the source, of their vagueness. 
vagueness. Indeed, Sorensen himself explicitly accepts that there is higher-order vagueness (1985; 2010). 4

The paper will proceed as follows. In $\$ 2$, I set out Sorensen's truthmaker-gap epistemicism in more detail. In $\mathbb{S} \mathbb{S}_{3}-4$, I set up the case against truthmaker-gap epistemicism, in terms of an incompatibility argument with higher-order vagueness. This constitutes the main argument of the paper. In $\$_{5}$, I argue that the truthmakergap epistemicist who avoids this problem by denying higher-order vagueness is saddled with an unattractive metaphysics. $\$ 6$ is a brief conclusion.

\section{Truthmaker-Gap Epistemicism}

In this section, I set out Sorensen's truthmaker-gap epistemicism in more detail. A truthmaker for proposition $\langle A\rangle$ provides a ground for that truth (Sorensen 200I, I65-I 84); a truthmaker for its negation $\langle\neg A\rangle$ provides a ground for $\langle A\rangle$ 's falsity. We can think of a truthmaker for $\langle\neg A\rangle$ as being a falsemaker for $\langle A\rangle$. When a proposition has neither a truthmaker nor a falsemaker, it is an ungrounded proposition. A commitment of epistemicism is that such propositions nevertheless have a truth-value: each proposition is true or false, whether grounded or not. So some truths have no ground. Indeterminate truths are ungrounded in this sense; they are indeterminate because they are ungrounded. Such truths correspond to no fact in the world (and are not knowable a priori), and so are utterly unknowable: there is absolutely no epistemic access to such truths. They are epistemic islands (200I, I75-6); epistemically, 'there is no way on to the island' (200I, I75). When a truth has a ground, by contrast, it corresponds to a fact in the world and so is at least in principle knowable. So by epistemicist lights, such truths are determinate truths.

I'll write ' $T x\langle A\rangle$ ' for ' $x$ is a truthmaker for $\langle A\rangle$ '. ${ }^{5}$ To say that a proposition is ungrounded is to say that it has neither a truthmaker nor a falsemaker: $\neg \exists x(T x\langle A\rangle \vee T x\langle\neg A\rangle) .^{6}$ Following Williamson (I999), I'll write ' $\triangle A$ ' for 'it is determinate that $A$ ' (i.e., determinate that $\langle A\rangle$ is true), and I'll write ' $\nabla A$ ' for

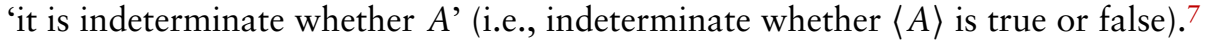

The key principles of truthmaker-gap epistemicism are then as follows:

(I) If $\langle A\rangle$ is indeterminate, then it is ungrounded. $\nabla A \rightarrow \neg \exists x(T x\langle A\rangle \vee T x\langle\neg A\rangle)$

4. Sorensen associates the existence of higher-order vagueness with the view that 'vague' is itself a vague predicate. This may or may not be the case; I do not rely on this assumption here.

5. I intend, as Sorensen does, to be completely neutral as to what kinds of entity serve as truthmakers. Note also that a truth may have many distinct truthmakers: 'there are people in India' has billions of truthmakers.

6. Note that $\langle\neg A\rangle$ is ungrounded iff $\langle A\rangle$ is.

7. Other authors write ' $\triangle A$ ' for the non-factive 'it is determinate whether $A$ ' (i.e., $\langle A\rangle$ is either determinately true or determinately false). It is most convenient here to use a factive determinacy operator on the model of the necessity operator ' $\square$ '. ' $\nabla$ ' is then the analogue of the contingency operator, not the possibility operator. 
(2) If $\langle A\rangle$ has a truthmaker, then it is a determinate truth.

$$
\exists x T x\langle A\rangle \rightarrow \triangle A
$$

For a large class of propositions, we can use (I) and (2) as definitions of ' $\nabla$ ' and ' $\triangle$ '. But Sorensen holds that (at least some) a priori truths are ungrounded (2005, 7I6), for they need no truthmaker to be true. And yet, since they are knowable, they must (by epistemicist lights) be determinate. For such a priori propositions $\langle A\rangle$,

(3) $A \leftrightarrow \triangle A$.

But for all non-a priori propositions,

(4) $\nabla A \leftrightarrow \neg \exists x(T x\langle A\rangle \vee T x\langle\neg A\rangle)$.

(5) $\triangle A \leftrightarrow \exists x T x\langle A\rangle$.

As an epistemicist theory, truthmaker-gap epistemicism accepts bivalence and classical logic in general (200I, 8), including conditional proof, and so (in contrast to supervaluationism) accepts that $A \vdash B$ iff $\vdash A \rightarrow B$. Sorensen allows additions to standard classical logic, including inference rules governing ' $\Delta$ ' and ' $\nabla$ ', as these only expand the set of valid inferences from those of classical first-order logic (200I, 8). But he will not allow 'deviant' logics, such as paraconsistent, relevant or intuitionistic logics, which subtract from the set of classically valid inferences (200I, 8-II). All classically valid inferences remain valid for the truthmaker-gap epistemicist. Because of this, truthmaker-gap epistemicism allows for true instances of ' $A \wedge \nabla A$ ' ${ }^{8}$ Whenever $\langle A\rangle$ is indeterminate, it is either the case that $A \wedge \nabla A$ or that $\neg A \wedge \nabla A$.

Given (3), (4), (5) and classical logic, we can establish the following principles (regardless of whether $A$ and $B$ are $a$ priori): ${ }^{9}$

$$
\begin{array}{ll}
\left(\triangle_{\mathrm{I}}\right) \text { If } \vdash A \text { then } \vdash \Delta A & (\nabla \mathrm{I}) \nabla A \leftrightarrow \nabla \neg A \\
\left(\triangle_{2}\right) \triangle(A \rightarrow B) \rightarrow(\triangle A \rightarrow \triangle B) & (\nabla 2) \nabla A \leftrightarrow \neg \Delta A \wedge \neg \Delta \neg A \\
\left(\triangle_{3}\right) \triangle A \rightarrow A &
\end{array}
$$

These principles (on which the logic of ' $\triangle$ ' is a normal modal logic at least as strong as KT) are common to most logics of vagueness. That they are validated by truthmaker-gap epistemicism goes some way to showing that it provides a sensible logic of vagueness.

I now turn to the argument that truthmaker-gap epistemicism is incompatible with higher-order vagueness.

8. Perhaps such instances are never assertable, since they cannot be known. Nevertheless, such instances can be true.

9. The proofs are all straightforward, and so I omit them here. 


\section{Troubles with Higher-Order Vagueness}

My case against truthmaker-gap epistemicism will be that it is incompatible with higher-order vagueness. Higher-order vagueness is vagueness in whether some case of the form $\triangle A$ or $\nabla A$ holds. If first-order vagueness is vagueness in whether $x$ has property $F$, then second-order vagueness is vagueness in whether it is determinate or indeterminate that $x$ has (or lacks) $F$. Where first-order vagueness for 'red' gives us borderline cases of redness, second-order vagueness for 'redness' gives us borderline cases of borderline cases of redness. ${ }^{\text {IO }} \mathrm{A}$ theory that allows secondorder vagueness for a predicate ' $F$ ' must allow instances of $\nabla \triangle F x, \nabla \triangle \neg F x$ and $\nabla \nabla F x \cdot{ }^{\text {II }}$ In general, a theory that allows for higher-order vagueness must allow instances of $\nabla \triangle A$ and $\nabla \nabla A$.

All such instances lead to absurdity within truthmaker-gap epistemicism. I'll show that truthmaker-gap epistemicism verifies the principle that whatever is determinate is determinately determinate:

(DD) $\triangle A \rightarrow \triangle \triangle A$

It is sometimes said that this principle alone rules out higher-order vagueness. But we need to be clear just what 'ruling out' means here. A theory with (DD) as a theorem can consistently contain ' $\nabla \Delta A$ ' and ' $\nabla \nabla A$ '. ${ }^{\text {I2 }}$ So (DD) does not rule out higher-order vagueness on logical consistency grounds. Rather, (DD) rules out higher-order vagueness by drawing absurd conclusions from any instance of ' $\nabla \Delta A$ ' or ' $\nabla \nabla A$ '. If $\nabla \triangle A$, then it should be open whether $\langle A\rangle$ is determinately true or indeterminate: both ' $\nabla \triangle A \wedge \triangle A$ ' and ' $\nabla \Delta A \wedge \neg \triangle A$ ' should be consistent. ${ }^{\text {I3 }}$ But given (DD), ' $\nabla \triangle A$ ' is inconsistent with ' $\triangle A^{\prime}$ ' (for ' $\nabla \Delta A^{\prime}$ ' entails ' $\neg \Delta \Delta A^{\prime}$ ). This is the sense in which (DD) rules out higher-order vagueness, and why (DD) 'is likely to be rejected in any plausible account of higher-order vagueness' (Williamson I999, I34). ${ }^{\text {I4 }}$

The case against truthmaker-gap epistemicism, therefore, will be that it is committed to (DD), which is incompatible (in the sense just described) with higherorder vagueness. The argument, in outline, goes as follows. Whether a truth $\langle A\rangle$

IO. In such a case, it is indeterminate whether the patch is indeterminately red. It is either unsettled whether the patch is determinately or indeterminately red, or else unsettled whether the patch is determinately or indeterminately non-red. (Note that a patch is indeterminately non-red iff it is indeterminately red.)

I I. Note that these are equivalent to $\nabla \neg \Delta F x, \nabla \neg \Delta \neg F x$ and $\nabla \neg \nabla F x$, respectively. The final sentence is also equivalent to $\nabla \nabla \neg F x$ and $\nabla \neg \nabla \neg F x$.

I 2. As Williamson (I999) shows, $\mathrm{KT}_{5}\left(=\mathrm{S}_{5}\right)$ is the weakest normal modal logic which permits vagueness whilst being inconsistent with higher-order vagueness. So $\mathbf{K T}_{4}\left(=\mathrm{S}_{4}\right)$, which is strictly weaker than $\mathrm{KT}_{5}$, is at least consistent with instances of higher-order vagueness. Truthmaker-gap epistemicism is at least as strong as $\mathrm{KT}_{\mathbf{4}}$, but is weaker than $\mathrm{KT}_{\mathbf{5}}$. My claim is that, whilst truthmaker-gap epistemicism is logically consistent with instances of higher order vagueness, it is nevertheless absurd to combine truthmaker-gap epistemicism with such instances.

I3. This is not the case in every account vagueness, since some accounts deny that ' $\nabla A \wedge A$ ' can ever be true. But truthmaker-gap epistemicism is committed to such instances by its adherence to classical bivalence.

I4. Indeed, Sorensen $(2010,399)$ explicitly rejects the principle ' $\nabla \nabla A \rightarrow \nabla A$ ', which is entailed by (DD). 
is determinate or indeterminate turns on the existence of a truthmaker for $\langle A\rangle$, according to truthmaker-gap epistemicism. But existence is always a determinate matter, and whether some entity is a truthmaker for $\langle A\rangle$ is likewise always a determinate matter, according to truthmaker-gap epistemicism. Or so I claim: I'll argue for each of these premises in detail below. If we grant them, then it is always determinate whether a truthmaker for $\langle A\rangle$ exists. If $\langle A\rangle$ in fact has a truthmaker, then it is determinate that $\langle A\rangle$ has a truthmaker. But, given the truthmaker-gap analysis of determinacy, it follows that if $\langle A\rangle$ is determinate, it is determinately determinate: if $\triangle A$ then $\triangle \triangle A$, just as (DD) says. My aim in the next section, therefore, is to show that truthmaker-gap epistemicism is indeed committed to the two premises required by this argument.

\section{The Incompatibility Argument}

My aim in this section is to establish the two claims made at the end of the previous section, that according to truthmaker-gap epistemicism:

(DE) Existence is always a determinate matter: $x$ exists $\rightarrow \Delta x$ exists.

(DT) Truthmaking is always a determinate matter: $\operatorname{Tx}\langle A\rangle \rightarrow \triangle T x\langle A\rangle$.

The argument for $(\mathrm{DE})$ is simple. Take any existential statement $\langle x$ exists $\rangle$. Trivially, it depends for its truth on the existence of $x$. If $x$ exists, then $\langle x$ exists $\rangle$ is true and, moreover, is true in virtue of $x$ 's existence. In other words, the very entity that witnesses the truth of $\langle x$ exists $\rangle$ is a truthmaker for that truth. These are paradigm cases of truthmaking. So, if $x$ exists then $\langle x$ exists $\rangle$ has a truthmaker. But if $\langle x$ exists $\rangle$ has a truthmaker, then $\langle x$ exists $\rangle$ is determinately true (according to truthmaker-gap epistemicism) and hence it is determinate that $x$ exists. So if $x$ exists, then it is determinate that $x$ exists, just as (DE) says.

The argument for (DT) requires a little more argument. In outline, the case is this. First, if $x$ is a truthmaker for $\langle A\rangle$ then, necessarily, $x$ is a truthmaker for $\langle A\rangle$ if $x$ exists:

(6) $T x\langle A\rangle \rightarrow \square(x$ exists $\rightarrow T x\langle A\rangle)$

Second, whatever is a necessary truth is a determinate truth:

(7) $\square A \rightarrow \triangle A$

I'll argue below that truthmaker-gap epistemicism is committed to both (6) and (7). If so, we can argue for (TM) as follows. Assume that $T x\langle A\rangle$. By (6), we have $\square(x$ exists $\rightarrow T x\langle A\rangle)$ and so, by $(7)$, we have $\Delta(x$ exists $\rightarrow T x\langle A\rangle)$. Given $\left(\triangle_{2}\right)$, this entails that $\Delta x$ exists $\rightarrow \triangle T x\langle A\rangle$. Given our assumption that $T x\langle A\rangle$, we infer that $x$ exists and hence, by (DE), $\triangle x$ exists. Modus ponens on the previous result then gives us $\triangle T x\langle A\rangle$. Discharging the assumption, we have shown that if $T x\langle A\rangle$ then $\triangle T x\langle A\rangle$, just as (DT) says. 
Why should a truthmaker-gap epistemicist accept (6)? One reason is that it captures (part of) what most philosophers mean by truthmaking. ${ }^{15}$ As RodriguezPereyra (2006a, I88) notes, (6) is accepted by the majority of truthmaker theorists, including Armstrong $(2004,5)$, Cameron (2008, 28; 2007, 4I3, 42I), Fox (I987, I89), Lewis (2003, 28), Restall (I996, 332) and Rodriguez-Pereyra (2006b, 332). Since truthmaker-gap epistemicism is supposed to appeal to the standard use of 'truthmaker', this is some (but clearly not conclusive) evidence in favour of (6).

One might try to resist (6) by holding that the truth of a proposition depends on both the existence of a truthmaker and the way that truthmaker is. The truthmaker for $\langle$ Boris is fat $\rangle$, on this view, is just Boris himself. But whether 〈Boris is fat $\rangle$ is true depends not only on Boris existing, but also on whether he is fat. Boris may exist and yet not be fat, in which case, he would not be a truthmaker for Boris is fat $\rangle$. In general, on the view under consideration, whether some $x$ is a truthmaker for $\langle A\rangle$ depends (in part) on how $x$ is and so (in general) the truthmaking relation will not hold of necessity.

The truthmaker-gap epistemicist cannot accept this notion of truthmaking. The view holds that Boris counts as a truthmaker for $\langle$ Boris is fat (according to world $w$ ) just in case he is fat (according to world $w$ ). But now suppose that Boris is fat. Then, on the view just sketched, Boris counts as a truthmaker for 〈Boris is fat . According to truthmaker-gap epistemicism, therefore, 〈Boris is fat is determinately true (since it has a truthmaker). Discharging the assumption, we have show that: if Boris is fat, then it is determinate that Boris is fat. But a truthmaker-gap epistemicist cannot accept this conclusion, for she must allow for the possibility that Boris is fat but indeterminately so. Consequently, the truthmaker-gap epistemicist has to reject the view of truthmaking just sketched: she must accept that the relationship between truthmaker and proposition is a necessary one. In other words, she must accept (6).

Why should a truthmaker-gap epistemicist accept (7)? Sorensen (200I, I73-4, I76) holds that non-a priori ungrounded truths are counterexamples to Bigelow's (I988) and Lewis's (I999) principle that truth supervenes on being. Sorensen calls such propositions epistemic islands: 'there is no access to [their] truth via a truthmaker' and so 'one cannot have objectively justified true belief[s]' in such propositions (200I, I75). This failure of supervenience (of the truths on the facts) entails that there are two possible worlds, alike with respect to the facts, which differ with respect to the truths. More precisely, for any borderline- $F$ case $x$, there are possible worlds $w$ and $w^{\prime}$ alike with respect to the facts such that $x$ is $F$ according to $w$ but non- $F$ according to $w^{\prime}$. The borderline between the $F$ s and the non-Fs shifts groundlessly between $w$ and $w^{\prime}$, according to Sorensen: it falls here or there but could easily have fallen elsewhere, even with all the worldly facts held constant. So if $x$ is a borderline $F$ (i.e., it's indeterminate whether $x$ is $F$ ), then it could have been $F$ and could have been non- $F$ (without any of the worldly

I 5. By 'truthmaker for $\langle A\rangle$ ', Fox (I987, I89) means 'something whose very existence entails $A$ '; Lewis $(2003,28)$ means an entity $x$ such that 'every world where $[x]$ exists is a world where $[A]$ is true'; and Restall $(\mathrm{I} 996,332)$ means ' $[x]$ exists, and it is impossible that $[x]$ exist without $A$ '. Rodriguez-Pereyra $(2006 \mathrm{~b}, 96 \mathrm{I}-2)$ argues that (6) must be true, 'otherwise, how could the proposition be true in virtue of the alleged truthmaker?'. 
facts changing). The point generalises. If it is indeterminate whether $A$, then $\langle A\rangle$ 's truth-value depends on where some particular borderline falls, but where that borderline falls is not itself fixed by the facts. That ungrounded borderline could have fallen elsewhere without the worldly facts changing, in such a way as to affect $\langle A\rangle$ 's truth-value: hence it is possible that $A$ and also possible that $\neg A$. Consequently, $\nabla A \rightarrow(\diamond A \wedge \diamond \neg A)$. Contraposing, we have $(\square \neg A \vee \square A) \rightarrow \neg \nabla A$. Since ' $\square$ ' is factive, we have $\square A \rightarrow(A \wedge \neg \nabla A)$ and hence $\square A \rightarrow \triangle A$, just as (7) says.

A truthmaker-gap epistemicist must accept (6) and (7), and consequently is committed to (DT), as well as to (DE). The argument from (DT) and (DE) to (DD), sketched in $\mathbb{S}_{3}$, is then as follows. Assume $\triangle A$. Given truthmakergap epistemicism, $\langle A\rangle$ has a truthmaker $t$, i.e. $T t\langle A\rangle$. Then (DT) entails that $\triangle T t\langle A\rangle$ and, since $t$ exists, (DE) entails that $\Delta t$ exists. From $\Delta T t\langle A\rangle \wedge \Delta t$ exists we infer that $\Delta(T t\langle A\rangle \wedge t$ exists $) .{ }^{16}$ Given truthmaker-gap epistemicism, the embedded ' $T t\langle A\rangle \wedge t$ exists' entails ' $\triangle A$ ' and so we infer from $\Delta(T t\langle A\rangle \wedge t$ exists $)$ to $\triangle \triangle A .{ }^{\mathrm{I} 7}$ Discharging the assumption, we have shown that, if $\triangle A$ then $\triangle \triangle A$, just as (DD) says. So truthmaker-gap epistemicism is indeed committed to (DD) and hence is incompatible with higher-order vagueness.

\section{Denying Higher-Order Vagueness}

Truthmaker-gap epistemicism is committed to (DD) (\$4), which rules out higherorder vagueness $\left(\mathbb{S}_{3}\right)$ : it is absurd to combine truthmaker-gap epistemicism with instances of higher order vagueness. As I argued in $\mathbb{S}_{I}$, this is a serious cost for Sorensen's general project of analysing vagueness in terms of absolute unknowability. Without truthmaker-gap epistemicism in play, Sorensen loses his explanation of why indeterminate truths are absolutely unknowable. An epistemicist must then say that something makes ' $n$ nanoseconds after noon is noonish' true and ' $n+1$ nanoseconds after noon is noonish' false. Explaining what could possibly do this is a serious challenge for epistemicism. Perhaps epistemicism is plausible; perhaps not. The point here is that the epistemicist is left with the heavy burden of explaining what makes ' $n$ nanoseconds after noon is noonish' true and ' $n+1$ nanoseconds after noon is noonish' false for some value of $n$.

What if an epistemicist, faced with this worry, wishes to adopt truthmaker-gap epistemicism whilst rejecting higher-order vagueness? ${ }^{\mathrm{I}} 8$ She will then hold that there can be no instance of $\nabla \triangle A$ or $\nabla \nabla A$, and so (DD) will be rendered trivially true and hence unproblematic. Consequently, this move avoids the argument I've given above. Yet the move is not a good option, as I'll argue for the remainder of this section.

I6. The inference is from ' $\triangle(A \wedge B)$ ' to ' $\triangle A \wedge \Delta B$ ', which holds in any normal modal logic and $a$ fortiori holds according to truthmaker-gap epistemicism, given $\left(\triangle_{\mathrm{I}}\right)$ and $\left(\triangle_{2}\right)$.

I7. The inference is from $A \vdash B$ and ' $\triangle A$ ' to ' $\triangle B$ ', which again follows from $\left(\triangle_{\mathrm{I}}\right)$ and $\left(\triangle_{2}\right)$.

I 8 . This would be a somewhat strange move, since epistemicism is perhaps the best-placed theory of vagueness to accept higher-order vagueness $(\mathbb{I})$. 
In accepting first-order but not higher-order vagueness, one accepts a logic of ' $\Delta$ ' at least as strong as $\mathrm{KT}_{5}$ (Williamson I999) and hence accepts the (E) principle:

$$
\text { (E) } \neg \triangle A \rightarrow \triangle \neg \triangle A
$$

In terms of truthmaker-gap epistemicism, this says that for every lack of a truthmaker, the statement of that lack of truthmaker must itself have a truthmaker:

$$
\text { (8) } \neg \exists x T x\langle A\rangle \rightarrow \exists y G y\langle\neg \exists x T x\langle A\rangle\rangle
$$

Consequently, every true statement concerning the existence or non-existence of a truthmaker must itself have a truthmaker. Questions of the existence or non-existence of facts cannot go ungrounded.

What kind of general metaphysical view could support this claim? Presumably, the world of facts permits gaps with respect to the facts about Boris (according to truthmaker-gap epistemicism) because of the kind of physical being Boris is. In contrast to the number I, or the set $\{\varnothing,\{\varnothing\}\}$, for instance, Boris can possess properties indeterminately and so the worldly facts may fail to answer certain meaningful questions about Boris. What goes for Boris goes for any other physical particulars and, presumably, also for physical events, physical qualities and so on. The picture would seem to be that there may be gaps in the facts concerning any physical entity. But not so, on the view under consideration: the one exception being facts about the physical facts themselves, which permit no gaps. ${ }^{\text {I9 }}$ This

single exception to the general rule looks ad hoc. What is it about the nature of physical facts, as opposed to the natures of other physical entities, that permits no gaps in the facts about those entities? I don't see that any answer can be given. The worry becomes even more pressing if we think of physical facts as being composed of physical particulars and properties (Armstrong 2004). If there may be fact-gaps concerning physical particulars and properties, then surely there may also be fact-gaps concerning entities comprised of physical particulars and properties (including facts). But not so, on the view under consideration.

To my mind, that makes the higher-order-vagueness-denying version of truthmaker-gap epistemicism an unappealing position to hold (even if it is in general plausible to deny that there is higher-order vagueness, which I doubt). This is, however, the only available version of truthmaker-gap epistemicism $\left(\mathbb{S}_{4}\right)$. That's sufficient reason to reject truthmaker-gap epistemicism.

\section{Conclusion}

Truthmaker-gap epistemicism tries to explain how there can be precise but unknowable cut-offs. For some $n$, ' $n$ nanoseconds after noon is noonish' is true whilst ' $n+1$ nanoseconds after noon is noonish' is false. This can be so, according

I9. Note that we have to think of these facts as physical entities, in order for them to play the right kind of worldly grounding role. 
to truthmaker-gap epistemicism, because ' $n$ nanoseconds after noon is noonish' is an ungrounded truth.

But truthmaker-gap epistemicism is incompatible with higher-order vagueness: any instance of higher-order vagueness leads to absurdity within the truthmakergap epistemicist's theory $\left(\mathbb{S}_{4}\right)$. This is a blow for Sorensen, who is explicit that there are instances of higher-order vagueness. The objection is not merely ad hominem, for it is highly plausible that Sorensen is correct in accepting higherorder vagueness. But even if not, truthmaker-gap epistemicism does not sit well with the denial of higher-order vagueness $\left(\mathbb{S}_{5}\right)$. So either way, truthmaker-gap epistemicism is not a tenable analysis of vagueness.

\section{References}

Armstrong, D. (2004). Truth and Truthmakers, Cambridge University Press, Cambridge.

Bigelow, J. (I988). The reality of numbers: A physicalist's philosophy of mathematics, Oxford University Press, Oxford.

Cameron, R. (2007). How to be a truthmaker maximalist, Nous 42(3): 4IO-42I.

Cameron, R. (2008). Truthmakers and necessary connections, Synthese I6I(I): 27-45.

Fox, J. (1987). Truthmaker, Australasian Journal of Philosophy 65(2): I 88-207.

Greenough, P. (2008). Indeterminate truth, Midwest Studies In Philosophy 32(I): 2I 3-24 I.

Lewis, D. (1999). A world of truthmakers?, Papers in Metaphysics and Epistemology, Cambridge University Press, pp. 2I 5-220.

Lewis, D. (2003). Things qua truthmakers, in H. Lillehammer and G. Rodriguez-Pereyra (eds), Real Metaphysics, Routledge, London, pp. 25-38.

Restall, G. (1996). Truthmakers, entailment and necessity, Australasian Journal of Philosophy 74(2): 33 I-40.

Rodriguez-Pereyra, G. (2006a). Truthmakers, Philosophy Compass I(2): I 86-200.

Rodriguez-Pereyra, G. (2006b). Truthmaking, entailment, and the conjunction thesis, Mind I I 5(460): 957-982.

Sorensen, R. (I985). An argument for the vagueness of 'vague', Analysis 45(3): I34-I37.

Sorensen, R. (I988). Blindspots, Oxford University Press, New York.

Sorensen, R. (1994). A thousand clones, Mind I03(409): 47-54.

Sorensen, R. (200I). Vagueness and Contradiction, Oxford University Press, Oxford.

Sorensen, R. (2005). A reply to critics, Philosophy and Phenomenological Research $7 \mathrm{I}(3): 7 \mathrm{I} 2-728$.

Sorensen, R. (2010). Borderline hermaphrodites: Higher-order vagueness by example, Mind I I9(474): 393-408. 
Williamson, T. (1994). Vagueness, Routledge, London.

Williamson, T. (I999). On the structure of higher-order vagueness, Mind Io8(429): I27I 43 . 